\title{
Insertion Related Infection Prevention with Vascular Access Devices
}

\author{
Michelle DeVries
}

\section{Abstract}

The goal of vascular access devices is to provide for the administration of the therapies required to help the patient recover while causing the least amount of damage to the patient's vascular system. One of the ways to preserve patient vasculature is through the prevention of infections associated with these devices. The central line bundle, created by Peter Pronovost in a landmark study known as the keystone study in Michigan, consists of five components that, when strictly adhered to during the insertion of a central line catheter, are known to reduce the risk of catheter-related BSIs. The five components include hand hygiene, maximal barrier precautions during insertion, use of chlorhexidine as a skin antisepsis, optimal catheter site selection with avoidance of the femoral vein for central venous access in adult patients, and daily review of line necessity with prompt removal of unnecessary lines. These five components to prevent infection during the insertion of a central catheter are reviewed within this chapter. Care and maintenance considerations, equally important in the prevention of infection, are covered in detail throughout the rest of this book.

M. DeVries $(\bowtie)$

Methodist Hospitals, Gary, IN, USA

Menzies Health Research Institute-Alliance for Vascular Access Teaching and Research (AVATAR) Group, Griffith University, Brisbane, QLD, Australia e-mail: infectionprevention@comcast.net

\section{Keywords}

CVAD infection prevention - Central line bundle . Personal protective equipment $\cdot$ Site selection · Device necessity

\subsection{Introduction}

A monumental amount of attention has been devoted to preventing infections during the insertion phase of a vascular catheter's life cycle. The very act of breaking the skin barrier and inserting a medical device directly through the vein wall and into the blood stream deserves special attention, as the patient's natural infection prevention barriers have been disrupted. Defining key infection prevention elements during the insertion of a central catheter (known as the central line bundle) and monitoring adherence to these elements has resulted in tremendously positive results; knowledge of and adherence to these protocols has become a core expectation for all healthcare environments (APIC 2015; The Joint Commission 2012). Due to the positive impact sustained by adhering to the central line bundle, these core elements (hand hygiene, maximal barrier precautions during insertion, use of chlorhexidine as a skin antisepsis, optimal catheter site selection with avoidance of the femoral vein for central venous access in adult patients, daily review of line necessity with prompt removal of unnecessary lines) deserve further review and understanding. 


\subsection{Hand Hygiene}

Since the days of Ignaz Semmelweis, hand hygiene has been a fundamental part of any infection prevention strategy (WHO 2009). Hand washing is the cornerstone to aseptic technique practiced by all medical professionals to decrease the risk of bacterial contamination and the transmission of microbes from patient to patient (PICC Excellence 2018).

The procedure for washing hands (Fig. 10.1) prior to insertion of a vascular access device or any invasive procedure as recommended by the World Health Organization is as follows (WHO 2015):

\section{With Soap and Water:}

1. Wet hands with water.

2. Apply enough soap to cover all hand surfaces.

3. Rub hands palm to palm.

4. Rub right palm over left dorsum with fingers interlaced. Repeat on other side.

5. Rub hands palm to palm with fingers interlaced.

6. Rub back of fingers to opposing palms with fingers interlocked.

7. Perform rotational rubbing of left thumb clasped in right palm and vice versa.

8. Perform rotational rubbing, backward and forward, with clasped fingers of right hand in left palm and vice versa

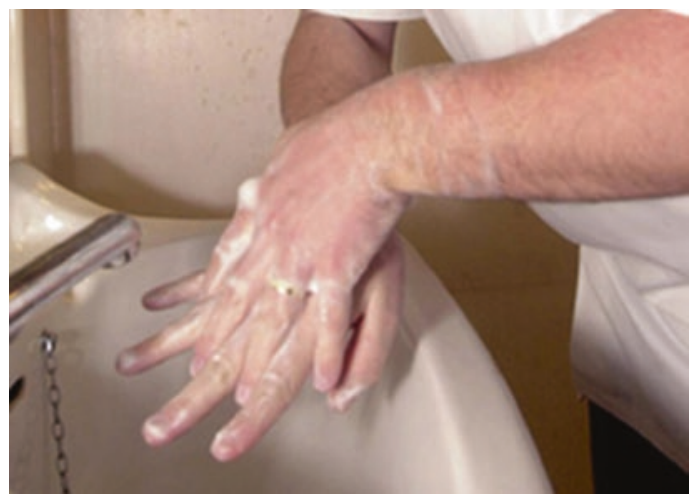

Fig. 10.1 Handwashing procedure. Used with permission N. Moureau PICC Excellence
9. Rinse hands thoroughly under running water. 10. Use clean paper towel to dry hands. Do not wave hands or blow on skin to dry.

11. Turn off faucet using same paper towel.

Alcohol-based waterless cleansing foam is extremely effective at reducing hand pathogens and can be used for intermittent hand cleansing in place of soap and water when hands are not visibly soiled (O'Grady et al. 2011b; Gorski et al. 2016).

\section{Hand Rub Procedure (WHO 2015):}

1. Apply a palm full of product in cupped hand and cover all surfaces.

2. Rub hands palm to palm.

3. Rub right palm over left dorsum with fingers interlaced and vice versa.

4. Rub hands palm to palm with fingers interlaced.

5. Rub backs of fingers to opposing palms with fingers interlocked.

6. Perform rotational rubbing of left thumb clasped in right palm and vice versa.

7. Perform rotational rubbing, backwards and forwards with clasped fingers of right hand in left palm and vice versa.

8. Allow to air-dry. Once dry, your hands are ready for your gloves.

Soap and water cleansing is still necessary after caring for patients who have Clostridium difficile as these spores are not susceptible to alcohol-based waterless cleansers (Gorski et al. 2016). Clostridium difficile has recently been renamed/reclassified as Clostridiodes difficile.

To protect the caregiver as well as the patient, gloves are used any time the hands will encounter blood or bodily fluids, or other potential pathogens, or when patients are on isolation precautions. Gloves are applied after hand hygiene has been performed, and hygiene is performed again following glove removal.

A summary of when handwashing/hand hygiene should occur and as well as hand hygiene requirements and recommendations according to each of the frequently referenced guidelines specific to vascular access is included 
Table 10.1 Handwashing requirements and recommendations per guidance publications

\begin{tabular}{|c|c|}
\hline $\begin{array}{l}\text { SHEA Compendium } \\
\text { (Marschall et al. } \\
\text { 2014) }\end{array}$ & $\begin{array}{l}\text { - Perform hand hygiene prior to catheter insertion or manipulation } \\
\text { - Use an alcohol-based waterless product or antiseptic soap and water } \\
\text { - Use of gloves does not obviate hand hygiene }\end{array}$ \\
\hline $\begin{array}{l}\text { Guidelines for the } \\
\text { Prevention of } \\
\text { Intravascular } \\
\text { Catheter-Related } \\
\text { Infections (O'Grady } \\
\text { et al. 2011a) }\end{array}$ & $\begin{array}{l}\text { - Perform hand hygiene procedures, either by washing hands with conventional soap and } \\
\text { water or with alcohol-based hand rubs (ABHR) } \\
\text { - Handwashing should be performed before and after palpating catheter insertion sites as } \\
\text { well as before and after inserting, replacing, accessing, repairing, or dressing an } \\
\text { intravascular catheter. Palpation of the insertion site should not be performed after the } \\
\text { application of antiseptic, unless aseptic technique is maintained }\end{array}$ \\
\hline $\begin{array}{l}\text { EPIC3 (Loveday } \\
\text { et al. 2014) }\end{array}$ & $\begin{array}{l}\text { - Decontaminate hands and wear a new pair of clean non-sterile gloves before manipulating } \\
\text { each patient's catheter. Decontaminate hands immediately following the removal of gloves } \\
\text { - When decontaminating hands using an alcohol-based hand rub, hands should be free of } \\
\text { dirt and organic material, and hand rub solution must come into contact with all surfaces } \\
\text { of the hand; hands should be rubbed together vigorously, paying particular attention to the } \\
\text { tips of the fingers, the thumbs, and the areas between the fingers, until the solution has } \\
\text { evaporated, and the hands are dry }\end{array}$ \\
\hline $\begin{array}{l}\text { CDC } \\
\text { Guide } \\
\text { (Preve }\end{array}$ & $\begin{array}{l}\text { - When hands are visibly dirty or contaminated with proteinaceous material or are visibly } \\
\text { soiled with blood or other body fluids, wash hands with either a non-antimicrobial soap } \\
\text { and water or an antimicrobial soap and water } \\
\text { - If hands are not visibly soiled, use an alcohol-based hand rub or an antimicrobial soap and } \\
\text { water for routinely decontaminating hands in all other clinical situations } \\
\text { - Decontaminate hands before donning sterile gloves when inserting a central intravascular } \\
\text { catheter } \\
\text { - Decontaminate hands before inserting indwelling urinary catheters, peripheral vascular } \\
\text { catheters, or other invasive devices that do not require a surgical procedure } \\
\text { - Decontaminate hands after removing gloves }\end{array}$ \\
\hline $\begin{array}{l}\text { INS Standards of } \\
\text { Practice(Gorski } \\
\text { et al. 2016) }\end{array}$ & $\begin{array}{l}\text { - Perform hand hygiene with an alcohol-based hand rub or antimicrobial soap and water } \\
\text { during patient care } \\
\text { - Before having direct contact with the patient } \\
\text { - Before donning sterile gloves when inserting a central intravascular catheter } \\
\text { - Before inserting a peripheral vascular catheter } \\
\text { - After contact with the patient's intact or non-intact skin } \\
\text { - After contact with body fluids or excretions, mucous membranes, and wound dressings } \\
\text { (if the hands are not visibly soiled) } \\
\text { - After contact with inanimate objects (including medical equipment) in the immediate } \\
\text { vicinity of the patient } \\
\text { - After removing gloves } \\
\text { - Use an alcohol-based hand rub routinely when performing hand hygiene unless the hands } \\
\text { are visibly soiled, or there is an outbreak of a spore-forming pathogen or norovirus } \\
\text { gastroenteritis }\end{array}$ \\
\hline $\begin{array}{l}\text { WHO Five Moments } \\
\text { for Hand Hygiene } \\
\text { (WHO 2009) }\end{array}$ & $\begin{array}{l}\text { - Wash hands only when visibly soiled; otherwise hand rub } \\
\text { - Hand rub before patient contact, before inserting catheters, after risk of exposure to bodily } \\
\text { fluids, after patient contact, and after contact with patient surroundings }\end{array}$ \\
\hline
\end{tabular}

in Table 10.1. Regardless of which guideline is followed, handwashing compliance is essential for the prevention of infections during the insertion and manipulation of any vascular access device. A framework for monitoring and reporting handwashing compliance as it relates to vascular access insertions and manipulations is essential to patient safety and should be included in all infection control and vascular access programs.

\subsection{Maximal Barrier Precautions}

The purpose of maximal sterile barrier precautions is to establish an aseptic barrier minimizing the passage of microorganisms from non-sterile to sterile areas. Central venous catheter procedures are to be treated as surgical procedures, using maximum sterile full-body drapes, taking special care in the application of gloves and 
immediately managing any episodes of contamination. Maximal barriers include (Marschall et al. 2014):

- Non-sterile caps and masks

- Sterile gown

- Sterile gloves

- Sterile large full-body drapes

The clinician wears the gown, cap, gloves, and mask to protect the patient from the clinician's microorganisms, and the patient is covered in full-body drapes to protect the patient from having his own microorganisms or bed microorganisms move from non-treated areas into areas that have been cleaned in an aseptic manner.

\subsubsection{Sterile Gown}

The sterile gown is used as part of the insertion procedure to prevent the transfer of microbes from the clinician to the patient, reducing the risk of infection. The sterile gown, which should be donned prior to donning sterile gloves, is folded so that the clinician can don the gown in a manner that maintains sterility. The clinician slips hands through the armholes and moves the arms in an outward motion, being careful not to touch any non-sterile items in the area. The gown unfolds, covering the clinician's arms and shoulders. An assistant can then grasp the strings and tie the gown behind the clinician's neck. To avoid contamination of the sleeves, hands should not be put through the sleeves and out the open end of the gown; keep cuffs of gown well over hands. Once gown is on and tied, it is time to don the sterile gloves.

\subsubsection{Gloves}

Gloves are required for all intravascular insertion procedures. According to the CDC and INS, sterile gloves are to be worn for the insertion of all arterial, central venous and midline catheters (Gorski et al. 2016; O'Grady et al. 2011a). Requirement for the use of sterile versus non- sterile gloves for peripheral intravenous catheter (PIVC) insertions is in a period of evolution. The $\mathrm{CDC}$ recommendations indicate that clean gloves for the insertion of PIVC, but sterile gloves if the site is re-palpated (O'Grady et al. 2011a). INS standards specify the use of a new pair of disposable, non-sterile gloves for peripheral intravenous insertions if Standard-ANTT is being used (no re-palpation of the site after asepsis) throughout the insertion procedure but suggests increased attention to aseptic technique and consideration of sterile gloves, as well as contamination concerns with the use of clean versus sterile gloves (Gorski et al. 2016).

\subsubsection{How to Don Sterile Gloves}

Donning sterile gloves requires a specific technique and some preparation. The following procedure is recommended (PICC Excellence 2018):

1. Open the sterile pack prior to donning gown so that the gloves can be accessed easily. The gloves are folded and cuffed exposing the inner glove so that the outer glove is not touched by the hand.

2. Grasp the cuff of one glove with the fingertips of the opposite hand which is still covered by the sterile gown sleeve. This way, only the sterile gown touches the sterile glove.

3. Slip hand into glove and pull the cuff over to unroll glove and cover hand and sleeve cuff.

4. Using the gloved hand, open the second glove from underneath the cuff allowing the sterile glove to touch the sterile portion of the second glove; slide second hand into glove and unfold to cover hand and sleeve cuff.

\section{Important tips (PICC Excellence 2018):}

1. Always overlap sterile gown with glove cuffs.

2. It is essential to avoid touching non-sterile items once sterile gloves are applied; the hands and fingers may be kept interlaced and in front of you at or above waist level to avoid inadvertent contamination. 
3. When clean gloves are used there is also potential for contamination by touching environmental surfaces prior to handling insertion supplies. Change clean gloves immediately before an invasive procedure such as VAD insertion.

4. Refrain from adjusting the mask or scratching the nose once sterile gloves are in place.

5. Any break or tear in the sterile gloves or touching the sterile glove to a non-sterile surface requires immediate removal with gown cuffs pulled down and application of new sterile gloves.

Audits may be performed to not only assess the appropriate application and use of gloves but also provide a more careful review of glove usage including considerations such as maintaining sterility and changing gloves when contaminated.

\subsubsection{Sterile Drapes}

A full-body sterile drape is placed on the patient to minimize the movement of microorganisms into the site selected for the catheter insertion procedure and to prevent contamination of the catheter prior to insertion into the bloodstream by allowing it to touch only the sterile surface of the full-body drape. Once the sterile drape is positioned, it is not moved or rearranged. Keep in mind that once a patient is draped, only the top surface of the draped area is considered sterile. Areas where skin is exposed, such as with a fenestration, should be skin adherent to avoid contamination from un-prepped skin. Exposed skin, regardless of prepping, remains a source of contamination. Do not touch skin with gloved hands or with the catheter.

\subsection{Patient Skin Preparation}

Skin preparation using chlorhexidine is another step in the central line bundle known to reduce the risk of infection. Two distinct steps must be performed prior to penetrating the skin barrier for the insertion of a vascular access device: the skin at and near the insertion site must be cleaned of any visible soil, and the insertion site must be prepared with an antiseptic agent (Gorski et al. 2016).

Many clinicians choose to cleanse the skin with soap and water or a skin cleansing wipe or other product formulation (Garland et al. 1995). This may help reduce the bioburden and the risk of inactivation of the antimicrobial solution if proteinaceous materials are present. However, a large French study failed to identify a difference in infection rates when a detergent cleansing was added prior to application of the antiseptic agent (Mimoz et al. 2015).

Chlorhexidine bathing is effective in reducing the bioload on the body especially when the chlorhexidine is applied without rinsing. Routine bathing of patients with chlorhexidine results in reduction of CLABSI. Randomized trials, metaanalyses, and guideline recommendations provide a strong basis for this practice (Timsit et al. 2018).

\subsection{Appropriate Skin Decontamination}

Once the skin is cleaned, it is ready to be prepared with an antiseptic. While alcohol and betadine offer some antimicrobial benefit, chlorhexidine gluconate $(\mathrm{CHG})$ has become the standard for skin preparation prior to IV insertions for patients greater than 2 months old. According to the label, CHG must be used with caution in children less than 2 months of age. Commercially available preparations of $\mathrm{CHG}$ are combined with alcohol to achieve rapid kill as well as persistence. Early studies strongly supported the use of CHG over povidone-iodine for skin preparations (Maki et al. 1994). The CDC recommends $>0.5 \%$ chlorhexidine $(\mathrm{CHG})$ with $70 \%$ alcohol as the antiseptic of choice (O'Grady et al. 2011a). A recent study by McCann et al. did not find a statistically significant improvement in CLABSI rates when increasing CHG to $2 \%$ in alcohol over more routinely used concentrations (McCann et al. 2016). While no agent can completely rid the skin of every microorganism, $\mathrm{CHG}$ is proven to be effective over the most common infecting microbes. Chlorhexidine is recommended both for its broad-spectrum 
action on bacteria, viruses, and fungi and its residual effect. $\mathrm{CHG}$ provides continual residual killing action for 48-72 $\mathrm{h}$ after application. Label claims vary per formulation, but at least one product now has a label claim for a 7-day kill which may offer some benefits (Healthcare 2017).

With all products, understanding appropriate use requires careful reading of instructions prior to use. Each comes with specific instructions regarding appropriate application method, duration of scrub time and necessary dry time based on volume of product used and anatomical location. Ensuring that products are applied appropriately is a significant consideration that likely does not receive enough attention during process monitoring (Casey et al. 2017).

In general, the widely available skin disinfection products in the US market promote a frictional back and forth method of application using pressure as described below (Silva 2014):

Use the following technique to cleanse the catheter insertion site prior to catheter placement:

1. Apply antiseptic solution using a frictional back and forth motion until all applicator solution is used.

2. Allow antiseptic solution to air-dry (do not blow or blot dry).

Because chlorhexidine with alcohol dries much faster, it reduces the likelihood that the catheter will be inserted before bacteria have died. Regardless of the product selected, ensuring that the product has dried completely prior to application of the transparent dressing minimizes the risk of skin irritation.

\subsection{Ultrasound}

When ultrasound is used as part of the insertion process, the device's cleanliness and disinfection procedures need to be ascertained. For central and midline placement, the use of sterile gel and sterile probe cover during the insertion procedure is a standard practice. As with all medical equipment, cleaning and disinfection must follow manufacturer's recommendations and accepted infection control standards. Delicate transducers may require prod- ucts that are not routinely used in the organization. If non-sterile gel is used during the initial assessment, ensure that single use sterile packets are available for use during the insertion procedure. Ensure that maintenance of non-sterile versus sterile gels is consistent with recommended practices to reduce inadvertent contamination (Oleszkowicz et al. 2015).

The Association for Vascular Access (AVA) published Guidance on Transducer Disinfection that established the need to develop processes for transducer (probe) cleaning in conjunction with patient use, validation of clinician training, and use of commercially manufactured sheath for all patient-based activities that involve contact with blood/body fluids or non-intact skin, evaluate outcomes, and document performance and training (Association for Vascular Access 2018). Programs should also review recommendations for frequency of probe cable and unit disinfection beyond just the transducer, as contamination of these surfaces is also noted as a significant concern.

For ultrasound-guided PIVC insertion, clinicians have found success with varying levels of ANTT. Be aware of facility policies which dictate the frequency of cleaning the entire surfaces of equipment (not just the probe) particularly when caring for patients in isolation precautions. For the infection control considerations of this chapter, ultrasound may also have additional impact by decreasing the number of attempts necessary to gain access.

\subsection{Site Selection}

The selected site for catheter placement is a result of many factors including (Gorski et al. 2016):

- Risk consideration based on knowledge of skin flora concentrations (arm veins versus femoral)

- Diagnosis (how long will the catheter be in use)

- Therapy (what kind of infusions are required)

- Vessel health and size (looking for straight, non-stenosed, bouncy, large veins)

- Age of patient (infant vs. adult)

- Length of time treatment required 
Some areas of insertion, such as the neck or femoral area, are prone to higher infection rates than other sites (arm) due to high microbial counts, humidity, and difficulty in dressing adherence. These factors must be taken into consideration when selecting and disinfecting an insertion site. For example, the femoral site is generally avoided due to its heavy colonization; however, a more recent review article suggests that the risk of infection from this site may no longer be as disparate from other locations (Marik et al. 2012) as originally believed.

Tunneling a CVAD to an area of greater safety may improve outcomes as in the case of mid-thigh femoral vein insertion. Moving an insertion location from the groin, axilla, or neck onto the leg, mid-upper arm, or chest, respectively, improves the ability to maintain transparent dressing adherence, reduces contamination caused by dressing disruption, and moves the insertion location onto a more secure and stable platform.

When the internal jugular vein is selected, care must be given for optimal placement to allow for maintenance of an intact dressing, which may require updated insertion practices. An intact dressing provides an important barrier to microbial transmission. Understanding the importance of an intact dressing helps the inserter when considering various options for insertion site location.

The location of a PIVC can impact outcomes and failure rates. For peripheral devices, there has been much published in support of the use of the forearm as the preferred insertion site to promote longer dwell time; decrease pain, phlebitis, infiltration, and dislodgement; and facilitate patient self-care (Fields et al. 2012; Gorski et al. 2016; Wallis et al. 2014). Insertion in the forearm creates a stable location for securement and dressing. There are considerations for other locations and the ability to maintain an intact dressing such as present with devices located in the hand or antecubital fossa.

Careful assessment of specific anatomical characteristics along the vein path allows for planning of optimal needle insertion or exit site to minimize the risk related to ongoing care and maintenance of the device. This pre-insertion assessment should include an external visual inspection looking for optimal access sites (e.g., away from areas of flexion or skin irritation/compromise) and an internal inspection with use of ultrasound to determine vein path and health. The goal with any distal catheter tip placement is to maximize three factors.

\subsection{Daily Review of Line Necessity}

The most effective way to prevent catheterrelated BSI is to simply not have a catheter. As basic as this sounds, it is paramount to infection prevention. As soon as the catheter is no longer medically necessary, it should be removed. While this is a recommendation by many healthcare groups and authors, establishing a policy and process with measured staff compliance for daily review is rare.

When performing daily assessment on a patient with a catheter, consider the following questions:

- Is the catheter still necessary for treatment of this patient or just convenient (don't retain for convenience such as periodic blood draws)?

- Can the patient be switched to a peripheral IV or to oral medications?

- Are there any catheter-related complications?

- Are there alternative therapies that could be used that would allow for the removal of the line?

- Is therapy completed or being discontinued?

- Is the patient satisfied and comfortable with the current delivery of medications?

The goal of vascular access devices is to provide for the administration of the therapies required to help the patient recover while causing the least amount of damage to the patient's vascular system. As soon as it is determined that the vascular access device is no longer medically necessary, it should be removed from the patient. 


\subsection{Use of Insertion Checklists and Observers}

It is recommended that an observer be present during any central venous catheter (CVC) insertion procedure to ensure aseptic technique is maintained throughout the procedure (O'Grady et al. 2011a). The Society for Healthcare Epidemiology of America (SHEA) recommendations state, "CVC insertion should be observed by a nurse, physician or other healthcare personnel who has received appropriate education, is certified to perform the procedure and has received education in aseptic technique to ensure that aseptic technique is maintained" (Marschall et al. 2014). "This observer should be empowered to stop the procedure if breaches in aseptic technique are observed." Following a checklist during a central vascular insertion procedure has such a profound effect on patient safety that in 2013, the Agency for Healthcare Research and Quality named "bundles that include checklists to prevent central line-associated bloodstream infection (CLABSI)" one of the top 10 "strongly encouraged patient safety practices" (Chopra et al. 2013).

While specific procedures in aseptic technique have proven to reduce the risk of CLABSIs (central line bundle created by Peter Pronovost in the keystone study in Michigan (Pronovost et al. 2006)), without adherence to these practices, CLABSIs will continue to be a problem in healthcare facilities (Fig. 10.2). The purpose of an observer is not only to remind and affirm the use of ANTT through the use of a central line insertion procedure (CLIP) checklist (Fig. 10.3) but also to hold the inserter accountable to aseptic procedures during the insertion process (CDC and NHSN 2016). The observer follows a proce- dure checklist or CLIP form as established by the facility and is responsible to check off each step as the inserter performs each required protocol. Adherence to protocol is a must in the reduction of central line infections.

The use of CLIP was introduced with the expectation that it would be completed by a trained observer (ideally empowered to stop the procedure in the event of a breach in sterile technique). There is some concern with the nursing insertion teams at times being staffed without the ability to have a trained observer. Expert consensus is that it is not ideal to assess one's own compliance with Surgical-ANTT; expanding practice to allow a trained observer to be present is in the best interest of patient safety (of note, this need not be another vascular access nurse or even another registered nurse but can be accomplished by another staff member with adequate training). Work continues to be published evaluating the impact of care bundles and checklists as effective means to improve outcomes (Blot et al. 2014).

Although not as commonplace with peripheral devices, there are precedents for the use of PIVC insertion and maintenance bundles. In the United Kingdom, the Saving Lives campaign gave consideration to both aspects of PIVC insertion and management including the provision of audit tools to assess bundle compliance (Slyne et al. 2012). In Spain, researchers reported improved outcomes after establishing bundles focused on reducing phlebitis and infection related to peripheral devices (Mestre et al. 2013). In the United States, the concept of an insertion and maintenance bundle (Table 10.2) was successfully used when adopting a policy to allow longer dwell of short peripheral catheters (DeVries et al. 2016; Devries and Valentine 2016). 
Checklist for Prevention of Central Line

Associated Blood Stream Infections

Based on 2011 CDC guideline for prevention of intravascular catheter-associated bloodstream infections:

https://www.cdc.gov/infectioncontrol/quidelines/bsi/index.htm/

Strategies to Prevent Central Line-Associated Bloodstream Infections in Acute Care Hospitals: 2014 Update

http://www.jstor.org/stable/10.1086/676533

For Clinicians:

Follow proper insertion practices

$\square$ Perform hand hygiene before insertion.

$\square$ Adhere to aseptic technique.

$\square$ Use maximal sterile barrier precautions (i.e., mask, cap, gown, sterile gloves, and sterile full body drape).

$\square$ Choose the best insertion site to minimize infections and noninfectious complications based on individual patient characteristics.

- Avoid femoral site in obese adult patients.

$\square$ Prepare the insertion sitewith $>0.5 \%$ chlorhexidine with alcohol.

$\square$ Place a sterile gauze dressing or a sterile, transparent, semipermeable dressing over the insertion site.

$\square$ For patients 18 years of age or older, use a chlorhexidine impregnated dressing with an FDA cleared label that specifies a clinical indication for reducing CLABSI for short term non-tunneled catheters unless the facility is demonstrating success at preventing CLABSI withbaseline prevention practices.

Handle and maintain central lines appropriately

$\square$ Comply with hand hygiene requirements.

Bathe ICU patients over 2 months of age with a chlorhexidine preparation on a daily basis.

$\square$ Scrub the access port or hub with friction immediately prior to each use with an appropriate antiseptic (chlorhexidine, povidone iodine, an iodophor, or $70 \%$ alcohol).

$\square$ Use only sterile devices to access catheters.

$\square$ Immediately replace dressings that are wet, soiled, or dislodged.

$\square$ Perform routine dressing changes using aseptic technique with clean or sterile gloves.

- Change gauze dressings at least every two days or semipermeable dressings at least every seven days.

- For patients 18 yearsof age or older, use a chlorhexidine impregnated dressing with an FDA cleared label that specifies a clinical indication for reducing CLABSIfor short-term non-tunneled catheters unless the facility is demonstrating success at preventing CLABSI with baseline prevention practices.

$\square$ Change administrations sets for continuous infusions no more frequently than every 4 days, but at least every 7 days.

- If blood or blood products or fat emulsions are administered change tubing every 24 hours.

- If propofol is administered, change tubing every 6-12 hours or when the vial is changed.

Promptly remove unnecessary central lines

$\square$ Perform daily audits to assess whether each central line is still needed.

\section{For Healthcare Organizations:}

$\square$ Educate healthcare personnel about indications for central lines, proper procedures for insertion and maintenance, and appropriate infection prevention measures.

$\square$ Designate personnel who demonstrate competency for the insertion and maintenance of central lines.

$\square$ Periodically assess knowledge of and adherence to guidelines for all personnel involved in the insertion and maintenance of central lines.

$\square$ Provide a checklist to clinicians to ensure adherence to aseptic insertion practices.

$\square$ Reeducate personnel at regular intervals about central line insertion, handling and maintenance,and whenever related policies, procedures, supplies, or equipment changes.

$\square$ Empower staff to stop non-emergent insertion if proper procedures are not followed.

$\square$ Ensure efficient access to supplies for central line insertion and maintenance (i.e. create a bundle with all needed supplies).

$\square$ Use hospital-specific or collaborative-based performance measures to ensure compliance with recommended practices.

Supplemental strategies for consideration:

$\square$ Antimicrobial/Antiseptic impregnated catheters

$\square$ Antiseptic impregnated caps for access ports

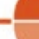

Fig. 10.2 Checklist for prevention of central line-associated bloodstream infections (Center for Disease Control 2011) https://www.cdc.gov/HAI/pdfs/bsi/checklist-for-CLABSI.pdf 
Page 1 of 2

Central Line Insertion Practices Adherence Monitoring

${ }^{*}$ required for saving

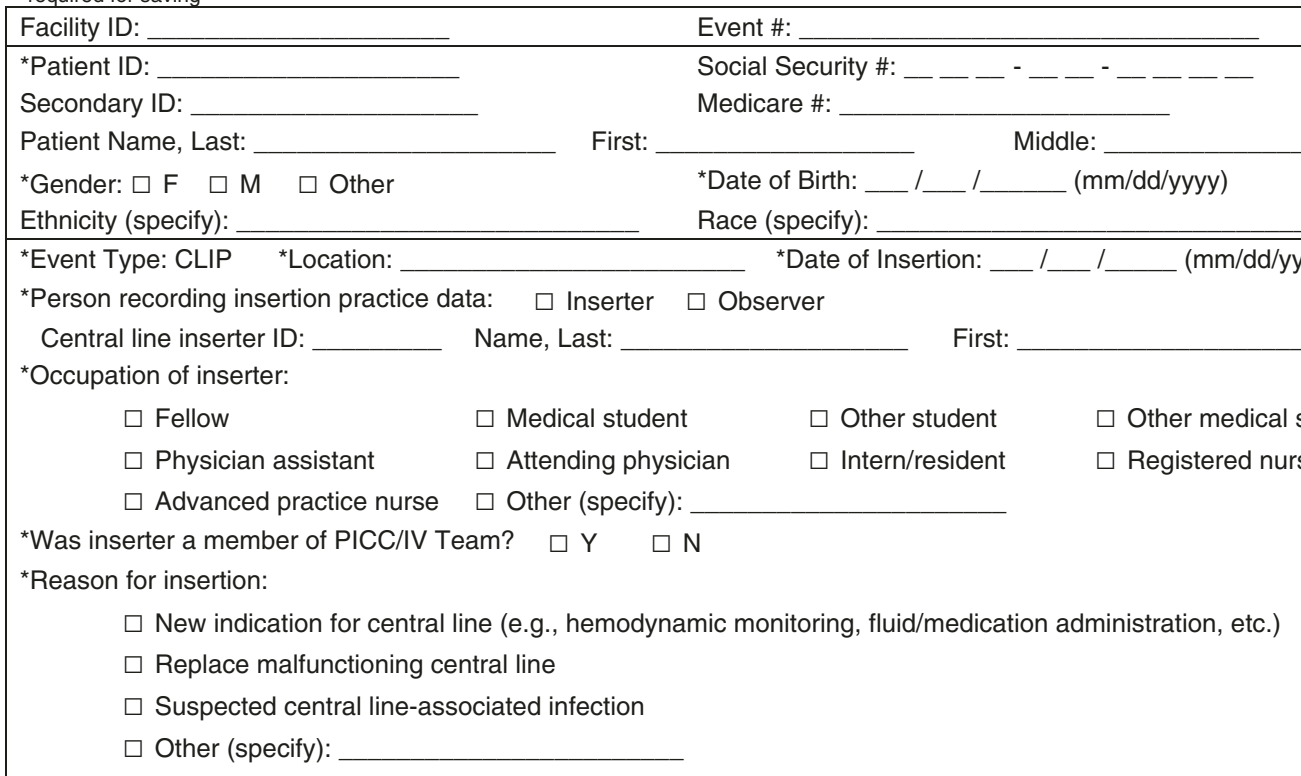

If Suspected central line-associated infection, was the central line exchanged over a guidewire? $\square \mathrm{Y} \square \mathrm{N}$ *Inserter performed hand hygiene prior tocentral line insertion: $\quad \square Y \quad \square N \quad$ (if not observed directly, ask inserter) *Maximal sterile barriers used: Mask $\square \mathrm{Y} \square \mathrm{N} \quad$ Sterile gown $\square \mathrm{Y} \square \mathrm{N}$ Large sterile drape $\square \mathrm{Y} \square \mathrm{N}$ Sterile gloves $\square \mathrm{Y} \square \mathrm{N} \quad$ Cap $\square \mathrm{Y} \square \mathrm{N}$ *Skin preparation (check all that apply) $\quad \square$ Chlorhexidine gluconate $\quad \square$ Povidone iodine $\quad \square$ Alcohol $\square$ Other (specify):

If skin prep choice was not chlorhexidine, was there a contraindication to chlorhexidine? $\square \mathrm{Y} \quad \square \mathrm{N} \quad \square \mathrm{U}$ If there was a contraindication to chlorhexidine, indicate the type of contraindication:

$\square$ Patient is less than 2 months of age - chlorhexidine is to be used with caution in patients less than 2 months of age

$\square$ Patient has a documented/known allergy/reaction to $\mathrm{CHG}$ based products that would preclude its use

$\square$ Facility restrictions or safety concerns for CHG use in premature infants precludes its use

*Was skin prep agent completely dry at time of first skin puncture? $\square \mathrm{Y} \square \mathrm{N}$ (if not observed directly, ask inserter) *Insertion site: $\quad \square$ Femoral $\square$ Jugular $\quad \square$ Lower extremity $\quad \square$ Scalp $\quad \square$ Subclavian $\quad \square$ Umbilical $\quad \square$ Upper extremity Antimicrobial coated catheter used: $\square \mathrm{Y} \quad \square \mathrm{N}$

Assurance of Confidentiality: The voluntarily provided information obtained in this surveillance system that would permit identification of any individual or institution is collected with a guarantee that it will be held in strict confidence, will be used only for the purposes stated, and will not otherwise be disclosed or released without the consent of the individual, or the institution in accordance with Sections 304, 306 and 308(d) of the Public Health Service Act (42 USC 242b, 242k, and 242m(d)).

Public reporting burden of this collection of information is estimated to average 25 minutes per response, including the time for reviewing instructions, searching existing data sources, gathering and maintaining the data needed, and completing and reviewing the collection of information. An agency may not conduct or sponsor, and a person is not required to respond to a collection of information unless it displays a currently valid OMB control number. Send comments regarding this burden estimate or any other aspect of this collection ofinformation, including suggestions for reducing this burden to CDC, Reports Clearance Officer, 1600 Clifton Rd., MS D-74, Atlanta, GA 30333, ATTN: PRA (0920-0666).

CDC 57.125 (Front) Rev 5 , v8.8

Fig. 10.3 Central line insertion practices (CLIP) monitoring form (CDC and NHSN 2016) https://www.cdc.gov/nhsn/ forms/57.125_CLIP_BLANK.pdf 
Table 10.2 Clinical bundle modified (DeVries et al. 2016)

\begin{tabular}{l|l}
\hline $\begin{array}{l}\text { Components of } \\
\text { protected clinical } \\
\text { bundle }\end{array}$ & Rationale \\
\hline $\begin{array}{l}\text { Chlorhexidine and } \\
\text { alcohol skin prep }\end{array}$ & $\begin{array}{l}\text { Provide adequate skin } \\
\text { disinfection of bacteria on } \\
\text { skin }\end{array}$ \\
\hline $\begin{array}{l}\text { Sterile gloves if } \\
\text { re-palpation of skin }\end{array}$ & Aseptic non touch technique \\
\hline $\begin{array}{l}\text { Intravenous catheter } \\
\text { with integrated } \\
\text { extension }\end{array}$ & $\begin{array}{l}\text { Reduces manipulation } \\
\text { consistent with INS } \\
\text { standards }\end{array}$ \\
\hline $\begin{array}{l}\text { Chlorhexidine } \\
\text { dressing }\end{array}$ & $\begin{array}{l}\text { Indicated to reduce skin } \\
\text { infections, skin colonization } \\
\text { and bloodstream infection }\end{array}$ \\
\hline Securement dressing & $\begin{array}{l}\text { Securement is strong element } \\
\text { in preventing catheter } \\
\text { movement }\end{array}$ \\
\hline $\begin{array}{l}\text { Alcohol disinfection } \\
\text { caps }\end{array}$ & $\begin{array}{l}\text { Provide intraluminal } \\
\text { protection }\end{array}$ \\
\hline
\end{tabular}

\section{Case Study}

A regional teaching hospital identified a rising rate of central line-associated bloodstream infections and wanted to verify the medical and nursing staff understood and applied the foundational principles of infection prevention to their insertion and maintenance practices with CVADs. Most of the infections were occurring in the early days following insertion, so the main emphasis was on insertion-related considerations.

A vascular access infection prevention committee was formed. The committee identified the foundational practices, standards, and guidelines from the Centers for Disease Control (CDC), Evidence-based Practices in Infection Control (EPIC), Society of Healthcare Epidemiology of America (SHEA), and others. They incorporated education on the central line bundle and checklist, evidence-based maintenance practices for aseptic technique, and prepared an evaluation tool for staff observation. A two-step process included education and observation to verify understanding of the foundational prin- ciples. Following the completion of the education, based on data collected during observation, it was decided that the central line bundle checklist required an independent observer to verify the steps. After analyzing the temporal association with this intervention with decreased early-onset infections, the committee determined the integration of the observer would provide a long-term solution for CVAD insertion infection prevention compliance in this teaching facility.

Due to the nature of changing medical staff and attrition among nursing staff, the committee was later deemed a permanent committee and went on to establish other methods to standardize infection prevention practices with all vascular access insertion and management at the hospital.

\section{Summary of Key Points}

1. The prevention of catheter-related BSIs is paramount to the preservation of vessel health.

2. Adhering to the components of the central line bundle during a central line insertion procedure has proven to be an effective way to prevent catheter-related BSIs.

3. The five components of the central line bundle include:

(a) Hand hygiene

(b) Maximal barrier precautions during insertion

(c) Use of chlorhexidine as a skin antisepsis

(d) Optimal catheter site selection with avoidance of the femoral vein for central venous access in adult patients

(e) Daily review of catheter necessity with prompt removal of unnecessary catheters 
4. As an infection prevention strategy, catheters should be removed as soon as they are deemed no longer medically necessary.

5. It is recommended that an observer be present during any central venous catheter (CVC) insertion procedure to ensure ANTT is maintained throughout the procedure.

6. The use of a checklist to prevent central line-associated bloodstream infection is one of the top 10 "strongly encouraged patient safety practices."

\section{References}

Apic. Guide to preventing central line-associated bloodstream infections, United States of America; 2015.

Association for Vascular Access. Guidance document transducer disinfection for assessment and insertion of peripheral and central catheters for vascular access teams and clinicians. In: Thompson J, Garrett JH, editors. www.avainfo.org; 2018.

Blot K, Bergs J, Vogelaers D, Blot S, Vandijck D. Prevention of central line-associated bloodstream infections through quality improvement interventions: a systematic review and meta-analysis. Clin Infect Dis. 2014;59:96-105.

Casey AL, Badia JM, Higgins A, Korndorffer J, Mantyh C, Mimoz O, Moro M. Skin antisepsis: it's not only what you use, it's the way that you use it. J Hosp Infect. 2017;96:221-2.

CDC, NHSN. National Healthcare Safety Network (NHSN) overview and Central Line Insertion Practices (CLIP); 2016.

Center for Disease Control. Checklist for prevention of central line associated blood stream infections [Online]. 2011. http://www.cdc.gov/HAI/pdfs/bsi/ checklist-for-CLABSI.pdf.

Chopra V, Krein SL, Olmsted RN, Safdar N \& Saint S. Prevention of central line-associated bloodstream infections: brief update review. Making health care safer II: an updated critical analysis of the evidence for patient safety practices. Rockville: Agency for Healthcare Research and Quality (US); 2013.

Devries M, Valentine M. Bloodstream infections from peripheral lines: an underrated risk. Am Nurse Today. 2016;11. https://www.americannursetoday.com/piv/.

Devries M, Valentine M, Mancos P. Protected clinical indication of peripheral intravenous lines: successful implementation. J Assoc Vasc Access. 2016;21:89-92.

Fields JM, Dean AJ, Todman RW, Au AK, Anderson KL, $\mathrm{Ku}$ BS, Pines JM, Panebianco NL. The effect of ves- sel depth, diameter, and location on ultrasound-guided peripheral intravenous catheter longevity. Am J Emerg Med. 2012;30:1134-40.

Garland J, Buck R, Maloney P, Durkin D, Toth-Lloyd S, Duffy M, Szocik P, Mcauliffe T, Goldmann D. Comparison of $10 \%$ povidone-iodine and $0.5 \%$ chlorhexidine gluconate for the prevention of peripheral intravenous catheter colonization in neonates: a prospect trial. Pediatr Infect Dis J. 1995;14:510-6.

Gorski L, Hadaway L, Hagle M, Mcgoldrick M, Orr M, Doellman D. Infusion therapy: standards of practice (supplement 1). J Inf Nurs. 2016;39(Suppl 1):S1-S159.

Healthcare P. Interventional care: prevantices [Online]. 2017. https://pdihc.com/all-products/prevantics. Accessed 4 Aug 2017

Loveday H, Wilson J, Pratt R, Golsorkhi M, Tingle A, Bak A, Browne J, Prieto J, Wilcox M. EPIC3: national evidence-based guidelines for preventing healthcareassociated infections in NHS Hospitals in England. J Hosp Infect. 2014;86:S1-70.

Maki DG, Ringer M, Alvarado CJ. Prospective randomized trial of povidone-iodine, alcohol, and chlorhexidine for prevention of infection associated with central venous and arterial catheters. Am J Infect Control. 1994;22:242.

Marik PE, Flemmer M, Harrison W. The risk of catheterrelated bloodstream infection with femoral venous catheters as compared to subclavian and internal jugular venous catheters: a systematic review of the literature and meta-analysis. Crit Care Med. 2012;40:2479-85.

Marschall J, Mermel L, Fakih M, Hadaway L, Kallen A, O'Grady N, Pettis A, Rupp M, Sandora T, Maragakis L, Yokoe D. Strategies to prevent central line-associated bloodstream infections in acute care hospitals: 2014 update. Infect Control Hosp Epidemiol. 2014;35:753-71.

Mccann M, Fitzpatrick F, Mellotte G, Clarke M. Is 2\% chlorhexidine gluconate in $70 \%$ isopropyl alcohol more effective at preventing central venous catheterrelated infections than routinely used chlorhexidine gluconate solutions: a pilot multicenter randomized trial (ISRCTN2657745)? Am J Infect Control. 2016;44:948-9.

Mestre G, Berbel C, Tortajada P, Alarcia M, Coca R, Fernández MM, Gallemi G, García I, Aguilar MC, Rodríguez-Baño J, Martinez JA. Successful multifaceted intervention aimed to reduce short peripheral venous catheter-related adverse events: a quasiexperimental cohort study. Am J Infect Control. 2013;41:520-6.

Mimoz O, Lucet J-C, Kerforne T, Pascal J, Souweine B, Goudet V, Mercat A, Bouadma L, Lasocki S, Alfandari S, Friggeri A, Wallet F, Allou N, Ruckly S, Balayn D, Lepape A, Timsit J-F. Skin antisepsis with chlorhexidine-alcohol versus povidone iodine-alcohol, with and without skin scrubbing, for prevention of intravascular-catheter-related infection (CLEAN): an open-label, multicentre, randomised, controlled, two-by-two factorial trial. Lancet. 2015;386:2069-77. 
O'Grady N, Alexander M, Burns L, Dellinger E, Garland J, Heard S, Lipsett P, Masur H, Mermel L, Pearson M, Raad I, Randolph A, Rupp M, Saint S, (Hicpac), H. I. C. P. a. C. Centers for Disease Control Guidelines for the prevention of intravascular catheter-related infections. Clin Infect Dis. 2011a;52:e162-93.

O'Grady N, Alexander M, Burns L, Dellinger E, Garland J, Heard S, Lipsett P, Masur H, Mermel L, Pearson M, Raad I, Randolph A, Rupp M, Saint S. Guidelines for the prevention of intravascular catheter-related infections. Center for Disease Control HICPAC Healthcare Infection Control Practices Advisory Committee: Guidelines for the prevention of intravascular catheterrelated infections. Center for Disease Control and Prevention; $2011 \mathrm{~b}$.

Oleszkowicz SC, Chittick P, Russo V, Keller P, Sims M, Band J. Infections associated with use of ultrasound transmission gel: proposed guidelines to minimize risk. Infect Control Hosp Epidemiol. 2015;33:1235-7.

Picc Excellence. Online course manuals. In: Moureau N, editor. 2018

Prevention CFDCA. Guideline for hand hygiene in healthcare settings: recommendations of the Healthcare Infection Control Practices Advisory Committee and the HICPAC/SHEA/APIC/IDSA Hand Hygiene Task Force. MMWR Recomm Rep. 2002;51(RR-16):1-45.

Pronovost P, Needham D, Berenholtz S, Sinopoli D, Chu H, Cosgrove S, Sexton B, Hyzy R, Welsh R, Roth G. An intervention to decrease catheter-related bloodstream infections in the ICU. N Engl $\mathrm{J}$ Med. 2006;355:2725-32.

Silva P. The right skin preparation technique: a literature review. J Perioper Pract. 2014;24:283-5.

Slyne H, Phillips C, Parkes J. Saving Lives audits: do they improve infection prevention and control practice? J Infect Prev. 2012;13:24-7.

The Joint Commission. Preventing central line-associated bloodstream infections: a global challenge, a global perspective [Online]. [Accessed] 2012.

Timsit J-F, Rupp M, Bouza E, Chopra V, Kärpänen T, Laupland K, Lisboa T, Mermel L, Mimoz O, Parienti J-J. A state of the art review on optimal practices to prevent, recognize, and manage complications associated with intravascular devices in the critically ill. Intensive Care Med. 2018;1-18.

Wallis M, Mcgrail M, Webster J, Marsh N, Gowardman J, Playford E, Rickard C. Risk factors for peripheral intravenous catheter failure: a multivariate analysis of data from a randomized controlled trial. Infect Control Hosp Epidemiol. 2014;35:63-8.

WHO. SAVE LIVES: clean your hands-WHO's global annual call to action for health workers [Online]. online: World Health Organization. 2015. http://www. who.int/gpsc/5may/en/. Accessed 9 Mar 2016, 2015.

World Health Organization. Historical perspective on hand hygiene in health care. WHO guidelines on hand hygiene in health care: First global patient safety challenge clean care is safer care. Genva; 2009.

Open Access This chapter is licensed under the terms of the Creative Commons Attribution 4.0 International License (http://creativecommons.org/licenses/by/4.0/), which permits use, sharing, adaptation, distribution and reproduction in any medium or format, as long as you give appropriate credit to the original author(s) and the source, provide a link to the Creative Commons license and indicate if changes were made.

The images or other third party material in this chapter are included in the chapter's Creative Commons license, unless indicated otherwise in a credit line to the material. If material is not included in the chapter's Creative Commons license and your intended use is not permitted by statutory regulation or exceeds the permitted use, you will need to obtain permission directly from the copyright holder. 